doi:10.12662/2359-618xregea.v8i1.p104-118.2019

ARTIGOS

\title{
SOCIALIZAÇÃO ORGANIZACIONAL EM CAMPUS DE INSTITUTO FEDERAL
}

\author{
ORGANIZATIONAL SOCIALIZATION IN CAMPUS OF \\ FEDERAL INSTITUTE
}

\section{SOCIALIZACIÓN ORGANIZACIONAL EN CAMPUS DE INSTITUTO FEDERAL}

\section{RESUMO}

O artigo objetiva descrever a percepção dos servidores de um Campus do IFB sobre processo de socialização organizacional e identificar dificuldades e necessidades de aperfeiçoamento. O estudo é teórico-empírico, descritivo, recorte transversal, abordagem mista, coleta de dados com questionário eletrônico e feitas análise de conteúdo e estatística descritiva. Foi usada amostragem não probabilística por conveniência com participação de $76 \%$ da população. Os resultados apontam que 51,5\% dos servidores participam em programa de integração, $55,9 \%$ em treinamento, $74,3 \%$ concordam que a integração contribuiu com o processo de adaptação e $84,2 \%$ obtêm conhecimento para executar as tarefas após o treinamento. Percebe-se a influência positiva da socialização organizacional no preparo do servidor ao exercício de suas funções. Apresentar a socialização organizacional como ferramenta estratégica, e as dificuldades e recomendações de melhoria das práticas de socialização foram as principais contribuições desta pesquisa para compreensão do fenômeno e como pontos de atenção para as organizações.

Palavras-chave: Socialização Organizacional. Servidor Público. Treinamento.

Adriana da Silva Correia Especialista em Gestão Pública (IFB). Administradora no Instituto Federal de Brasilia. Brasília - DF - BR. E-mail: $<$ adriana.correia@ifb.edu.br>.

\section{Lana Montezano}

Doutoranda em Administração pela Universidade de Brasília. Brasília - DF - BR. E-mail:

<lanaconsult@gmail.com>.

\section{ABSTRACT}

The article aims to describe the perception of IFB Campus servers about the process of organizational socialization and to identify difficulties and needs for improvement in it. The study is theoretical-empirical, descriptive and cross-sectional, mixed approach, data collection with electronic questionnaire and made content analysis and descriptive statistics. Non-probabilistic sampling was used for convenience with participation of $76 \%$ of the population. The results indicate that $51.5 \%$ of the servers participate in an integration program, $55.9 \%$ in training, $74.3 \%$ agree that the integration contributed to the adaptation process, and $84.2 \%$ obtain knowledge to perform the tasks after training. The positive influence of organizational socialization on 
the preparation of the server to the performance of its functions is perceived. Presenting organizational socialization as a strategic tool, and the difficulties and recommendations for improvement of socialization practices were the main contributions of this research to understanding the phenomenon and as points of attention for organizations.

Keywords: Organizational Socialization. Public Server. Training.

\section{RESUMEN}

El artículo tiene por objetivo describir la percepción de los servidores de un Campus del IFB sobre el proceso de socialización organizacional, e identificar dificultades y necesidades de perfeccionamiento. El estudio es teórico-empírico, descriptivo, recorte transversal, abordaje mixto, recolecta de datos con cuestionario electrónico y realizadas las analices de contenido y estadísticas descriptiva. Fue usada muestras no probabilísticas por conveniencia con participación de $76 \%$ de la populación. Los resultados apuntan que $51,5 \%$ de los funcionarios participan de programas de integración, $55,9 \%$ de capacitación, $74,3 \%$ concuerdan que la integración contribuye en el proceso de adaptación y $84,2 \%$ obtienen conocimiento para ejecutar las tareas después de la capacitación. Percibimos la influencia positiva de la socialización organizacional en el preparo del funcionario al ejercicio de sus funciones. Presentar la socialización organizacional como herramienta estratégica, y las dificultades y recomendaciones de mejoría de las prácticas de socialización fueron las principales contribuciones de esta pesquisa para comprensión del fenómeno y como puntos de atención para las organizaciones.

Palabras-clave: Socialización Organizacional. Funcionario Público. Capacitación.

\section{INTRODUÇÃO}

Devido às mudanças no contexto organizacional, um dos maiores desafios de uma organização é saber como gerir, integralizar e desenvolver o potencial de seu quadro funcional, visto que recebe indi- víduos com diferentes perfis profissionais, pontos de vista e anseios individuais. Nesse sentido, políticas de integração propiciam ambiente organizacional à adaptação de novos colaboradores (CUNHA, 2016). No setor público, exige-se um novo perfil do profissional: mais dinâmico, distinto, interativo, qualificado e que saiba realizar várias atividades dentro do contexto laboral (RIBEIRO; MANCEBO, 2013), além de passar a ser um propulsor de novas ideias para geração de resultados eficazes à sociedade (MARTINELLI; BRUM; WAECHTER, 2013).

Novos servidores contribuem com o acesso de diferentes tipos de conhecimentos e pluralidade de novas ideias, o que é muito válido no contexto organizacional, devido à diversidade das experiências e nível de instrução com que chegam às organizações públicas. No entanto, esses servidores precisam ser orientados ao entrar em exercício quanto à maneira eficiente de prestar o serviço à sociedade (IMAI; BOTOLOTO; BAPTISTA, 2013). Esse direcionamento no setor público precisa estar pautado na socialização organizacional desde a entrada do servidor (MARTINELLI; BRUM; WAECHTER, 2013), a fim de contribuir com a produtividade e motivação no trabalho (BRUM et al., 2014) e promover melhorias nesse ambiente e na vida pessoal e profissional, de modo a mudar a imagem negativa que a sociedade possui do servidor, ao considerá-lo ineficiente, acomodado, burocrático.

A socialização nos órgãos públicos está, cada vez mais, presente nos estudos acadêmicos, em que a gestão de pessoas é responsável por integrar e adaptar os novos servidores (CUNHA, 2016). Entretanto, a necessidade de melhorar e profissionalizar esses servidores dentro da gestão organizacional no ambiente público é notória e urgente (BORGES et al., 2010). Isso se deve à inevitável mudança que a administração pública precisa realizar dentro desse contexto, valorizando a satisfação do servidor dentro do órgão e ainda, constatando os resultados que o processo de socialização traz na produtividade e motivação dentro do ambiente de trabalho (BRUM et al., 2014).

Com isso, compreender como ocorre o processo de socialização dentro das Organizações Públicas se faz necessário, inclusive refere-se à recomendação de realização de investigações so- 
bre a temática, conforme foi apontado por Genari, Ibrahim, C. e Ibrahim, G. (2017). Dessa forma, esta pesquisa caracteriza-se como uma oportunidade para avaliar a questão do processo de socialização dos novos servidores e como esse pode influenciar na qualidade das atividades desempenhadas por eles, tanto na organização estudada como para outras instituições que possam ter contextos similares.

Nesse sentido, este artigo objetivou descrever a percepção dos servidores de um Campus de Instituto Federal sobre o processo de socialização organizacional, bem como identificar dificuldades e necessidades de aperfeiçoamento nesse processo para melhor desempenho de suas novas atribuições.

As principais contribuições deste estudo serão apresentar a socialização organizacional como uma ferramenta estratégica no ingresso do servidor ao ambiente público, a relevância do processo de integração e treinamento dos novos servidores, nos primeiros meses, após a entrada em exercício e avançar nos estudos sobre a temática no contexto de organizações públicas.

\section{REFERENCIAL TEÓRICO}

\subsection{SOCIALIZAÇÃO ORGANIZACIONAL}

O interesse em aprofundar na socialização organizacional diz respeito ao fazer parte do arcabouço de estudos da área de gestão de pessoas, principal responsável pela integração e adaptação dos novos servidores da organização, além de executar processos de seleção, treinamento, valorização dos colaboradores entre outros (CUNHA, 2016; GONDIM; SOUZA; PEIXOTO, 2013). O quadro 1 apresenta definições da socialização organizacional por diferentes autores.
Neste estudo, a socialização organizacional será considerada como processo de aprendizagem das competências necessárias e adaptação do servidor no novo ambiente de trabalho, a fim de executar as atribuições propostas pelo cargo. Há um elemento imprescindível para que essa execução seja eficiente e cause impactos positivos na prestação do serviço à sociedade, denominado, assim, de comportamento organizacional (ROBBINS, 2005), a qual é composto por diversas variáveis, entre elas a cultura organizacional que representa os valores e práticas da organização. Genari, Ibrahim, C. e Ibrahim, G. (2017) reforçam a relevância do processo de socialização organizacional para que o novo profissional passe a ter conhecimento acerca da cultura e possa assumir seu trabalho alinhados à ela.

Apesar da complexidade de cada variável do comportamento organizacional, os gestores terão a oportunidade impulsionar uma cultura organizacional robusta voltada ao compartilhamento de informações, à troca de conhecimento, à interação entre os indivíduos, à preparação para se adequar em ambientes variados de maneira rápida, bem como a prática do aprendizado social coletivo (ROBBINS, 2005; BEM; PRADO; DELFINO, 2013; LIMA, 2016). Acrescentam-se, ainda, o quesito comunicação, uma ferramenta relevante que consegue alinhar os objetivos individuais aos da organização, antevê possíveis embaraços, estreitar vínculos e impulsionar um ambiente favorável, pois indivíduos que se sentem parte da instituição tornam-se mais produtivos, realizando suas atribuições com mais eficiência (TIBURCIO; SANTANA, 2014).

Robbins (2005) ainda descreve que a socialização é composta de três estágios: pré-chegada, encontro e metamorfose, os quais impactam dire-

Quadro 1 - Definições de Socialização Organizacional

\begin{tabular}{|l|l|}
\hline \multicolumn{1}{|c|}{ Referência } & \multicolumn{1}{c|}{ Definição } \\
\hline $\begin{array}{l}\text { Van Maanen e Schein } \\
\text { (1979) }\end{array}$ & $\begin{array}{l}\text { Processo pelo qual o indivíduo adquire conhecimentos e habilidades sociais } \\
\text { necessários para assumir um papel organizacional. }\end{array}$ \\
\hline Chao (2012) & $\begin{array}{l}\text { Processo de aprendizagem e ajuste que permite ao indivíduo assumir um papel } \\
\text { organizacional que satisfaça as necessidades organizacionais e individuais. }\end{array}$ \\
\hline Silva e Fossá (2013) & $\begin{array}{l}\text { Processo de aprendizagem que se efetiva toda vez que um indivíduo experimenta } \\
\text { modificações de status, papel ou função em uma organização, e ainda como elemento } \\
\text { de fixação e manutenção da cultura organizacional. }\end{array}$ \\
\hline Moyson et al. (2017) & Processo que induz homogeneidade entre profissionais da mesma organização. \\
\hline
\end{tabular}

Fonte: elaborado pelas autoras. 
tamente na produtividade, no comprometimento individual com os objetivos organizacionais, e na decisão em permanecer no trabalho. $\mathrm{O}$ estágio de pré-chegada é o momento em que a organização reconhece que o novo colaborador que vai chegar, traz consigo valores, atitudes e expectativas individuais. A fase do encontro ocorre quando o funcionário é confrontado por dois lados distintos - o ambiente de trabalho em geral, as atividades, o chefe e os colegas - e a realidade. E o estágio da metamorfose dá-se devido às possíveis mudanças que o novo colaborador vai passar, especialmente quando tiver que solucionar certos problemas que apareceram no segundo estágio.

Delobbe, Cooper-Thomas e Hoe (2016), em pesquisa de um departamento de seleção das forças armadas de um país europeu, demonstraram que os recém-chegados com maior senso de comprometimento com suas atribuições no estágio de pré-entrada percebem o treinamento de maneira útil ao esclarecimento da função, pela troca existente de conhecimento com sua chefia e colegas.

A importância que as organizações devem dar à ampliação dos conhecimentos em relação ao processo de socializar os novos colaboradores permite promover a inclusão do indivíduo e fazê-lo sentir-se parte daquele novo ambiente. Isso produz dedicação em realizar atividades com eficiência e eficácia e aprimorar as qualidades e competências do profissional, visando ao êxito em sua profissão e ao sucesso da organização (MARTINELL; BRUM; WAECHTER, 2013).

\subsection{ESTRATÉGIAS DE SOCIALIZAÇÃO ORGANIZACIONAL}

Na busca pela otimização do processo de socialização organizacional, os gestores escolhem estratégias vislumbrando a melhor adaptação do recém-contratado à cultura local, pois, por intermédio delas, que a organização consegue transmitir seus valores e comportamentos para internalização do novo colaborador (SILVA et al., 2014). A integração e o treinamento correspondem a ferramentas estratégicas de socialização utilizadas pela área de gestão de pessoas, uma vez que visam auxiliar os novatos a se adequarem aos objetivos organizacionais, adaptarem com mais facilidade ao novo ambiente laboral e causarem impactos positivos no crescimento da própria organização (CUNHA, 2016).

Van Maanen (1996) definiu sete grupos de estratégias: formais (etapa inicial do processo) e informais (contato diário); individuais (aplicada individualmente) e coletivas (em grupo); sequenciais (processos contínuos) e não sequenciais (processos transitórios); fixas (cronograma pré-estabelecido) e variáveis (sem cronograma); por competição (atuação por conta própria) e por concurso (condições de competição iguais); em série (veteranos como tutores) e isoladas (sem processo de socialização); e por investidura (certificar o perfil adequado) e por despojamento (produzir resultados semelhantes).

Bauer et al. (2007) realizaram uma meta-análise na qual indicaram e testaram um modelo em que as táticas de socialização organizacional (formal, sequencial, fixa, serial e por investidura) geram efeitos positivos na clareza do papel do indivíduo no ambiente laboral, resultando em comprometimento organizacional, autoeficácia, relacionada ao desempenho e em aceitação social, diretamente ligada à satisfação no trabalho.

Cooper-Thomas, Anderson, e Cash (2012) realizaram um estudo, em uma grande organização de serviços profissionais, para analisar quais estratégias os novatos podem usar para simplificar seus processos de socialização organizacional, sendo elas: executar tarefas com habilidades e experiências para obter melhor desempenho, demonstrar habilidades, compartilhar informações, ser agradável, ser aberto e útil aos colegas, estar envolvido na equipe. Constaram que se pode maximizar a socialização por meio do fornecimento de manuais de procedimentos, orientação informal e com programas formais de integração.

Além da integração, outra ferramenta utilizada nas organizações é o treinamento que consiste na assimilação da cultura em curto prazo e visa aprendizagem das competências necessárias à execução de tarefas ou otimização no trabalho (MARRAS, 2009, p. 145). O treinamento é um fator-chave para melhor execução do trabalho e progresso funcional de novos servidores. Alinha- 
do a isso, entre as ações de gestão de pessoas, os treinamentos para servidores públicos são relevantes por contribuírem para a melhoria dos serviços oferecidos e para a satisfação do cidadão comum (PINTO; SILVA, 2015).

Observa-se que, quando a organização planeja e implementa a socialização de forma estratégica, os resultados alcançados podem ser visualizados pela consolidação do processo de aprendizagem promovido pela instituição e pelo desenvolvimento do novo profissional (SILVA et $a l ., 2014)$. Quando não há esse planejamento, a motivação dos servidores em aprender deixa de cumprir seu papel de aplicar, cotidianamente, em suas atividades os conhecimentos adquiridos e se condiciona somente ao aumento de sua remuneração (RIBEIRO et al., 2017).

\subsection{SOCIALIZAÇÃO ORGANIZACIONAL NO SETOR PÚBLICO}

Devido à reivindicação de serviços públicos de qualidade por parte dos cidadãos, os órgãos públicos têm percebido a necessidade da gestão com foco em resultados a fim de atender demandas com princípios da eficiência, eficácia e efetividade. Para isso, vêm desenvolvendo programas voltados à melhoria contínua de seus processos, visando à profissionalização do novo servidor para entendimento do seu papel na organização, compreensão e aplicação dos princípios na execução de suas tarefas (AIRES; FERREIRA, 2016; AMORIM; SILVA, 2012).

As organizações públicas têm-se preocupado em capacitar e qualificar seus servidores para prestarem serviços ágeis no atendimento às demandas sociais; minimizarem o excesso de burocracia nos processos, tornando-os mais céleres; ajudarem a ser eficientes no ambiente de trabalho e melhorarem no desempenho de suas atribuições (FREITAS, 2012). O objetivo primordial da integração é adaptar e treinar o novato o mais rápido possível, proporcionar segurança quando esse for executar suas tarefas e criar um ambiente acolhedor com os demais colegas (TEODORO, 2015).

Quando o colaborador chega à instituição e sente que está sendo acolhido por seus superiores e por seus pares, o tempo destinado ao comprometimento com os objetivos organizacionais e a identificação com o novo ambiente de trabalho é mais curto e eficaz (AMARO, 2016). Brum et al. (2014) mencionam que o processo de socialização não pode limitar-se no momento em que o servidor chega. É necessário um programa sistemático para integrar e treinar esse indivíduo a fim de promover melhorias contínuas na organização como um todo.

O estudo de Carvalho, Borges e Vikan(2012) em universidades públicas, comparando a socialização organizacional entre servidores brasileiros e noruegueses, identificou dois tipos de orientação cultural no Brasil que predominam na integração: tendência à evitação de incerteza, que consiste no preparo do servidor em relação ao conhecimento das atribuições, dos processos e da cultura para se sentir seguro na execução das tarefas; e a orientação tradicional, que enfatiza a questão do respeito à hierarquia, da aceitação e conformidade das normas. O resultado apontou média de 4,4 $(\mathrm{DP}=$ $0,6)$, visto que a maioria dos participantes se sente integrado à organização.

No estudo realizado em Instituto Federal de Ensino (IFE), Freitas (2012) constatou que o servidor tem vários motivos para participar de treinamentos: progressão na carreira, obter conhecimentos para a execução de tarefas, adquirir novas informações e, ainda, preparar-se para exercer um cargo. Para maioria dos servidores, o treinamento é visto como meio de adquirir conhecimentos para realizar suas atribuições com eficiência, reduzindo possíveis falhas, e desempenhar suas atividades para um serviço excelente no ambiente público. Já Teófilo et al. (2013), em pesquisa em uma empresa pública, defendem o treinamento no local de trabalho como mais eficaz, devido aos ganhos relacionados ao custo zero de deslocamento, ao repasse dos conhecimentos, à avaliação prática e à otimização do trabalho. A utilização dessa ferramenta coopera para o crescimento organizacional e para o desenvolvimento profissional do indivíduo.

Em pesquisa realizada em uma organização pública municipal do Rio Grande do Sul, Brum et al. (2014) concluíram a importância do processo de integrar os servidores no momento em que chegam ao órgão. Apesar de $92 \%$ conhecerem seus 
colegas, entendiam, superficialmente, as tarefas, causando impactos negativos na adaptação do novato. Por outro lado, $52 \%$ receberam orientações de seus colegas, e $66 \%$ relataram que essas orientações foram satisfatórias para executarem suas tarefas. Logo, eles veem a socialização como um fator relevante não apenas no ingresso, mas também durante toda a vida laboral do servidor.

Pacheco (2015) identificou, em pesquisa em uma Universidade Federal, que, para melhor entendimento das atividades, o servidor precisa participar de programas de treinamentos e obter informações do órgão em suas várias dimensões (tipo de serviço prestado, valores, princípios, missão e visão, normas, diretrizes institucionais). $\mathrm{O}$ treinamento teve $51 \%$ de participação dos servidores. Para o autor, a falta desses conhecimentos pode ter consequências, como dificuldade de adaptação e comprometimento no funcionamento das tarefas realizadas no setor. A partir dos resultados encontrados em outro IFE, $57 \%$ dos entrevistados destacaram a falta de conhecimento em relação às principais informações internas do órgão, e $72 \%$ não conheciam ou não participaram de programas formais de socialização (GENARI; IBRAHIM, C.; HIBRAIM, G., 2017).

No estudo de Cunha (2016), em uma universidade federal, $80,6 \%$ dos novos servidores participaram de programas de integração, 59\% consideraram os resultados dessa participação como bons ou excelentes, e 84,3\% afirmaram que esse programa contribuiu para o processo de adaptação. Depreendeu-se que a socialização organizacional é vista como uma importante ferramenta estratégica, uma vez que oportuniza tanto o conhecimento institucional, como a interação coletiva.

Gonçalves (2016), ao concluir seus estudos em uma instituição pública de ensino superior, enfatiza que os efeitos do treinamento interferem, positivamente, no comportamento do servidor e em suas atribuições, contribuindo, de maneira profícua, em seu desenvolvimento pessoal, profissional e intelectual. Isso refletiu no resultado da pesquisa, uma vez que $77 \%$ dos servidores ficaram satisfeitos em participar de treinamentos e aplicaram os conhecimentos adquiridos em suas tarefas; e, ainda, 91,5\% compartilharam esses conhecimentos com seus colegas.

\section{MÉTODO}

Este artigo é teórico-empírico por ter buscado fundamentação teórica na realização da pesquisa de campo para o conhecimento de como a socialização ocorre na prática. A pesquisa possui natureza descritiva, pois buscou descrever o comportamento do fenômeno estudado (HAIR JUNIOR et al., 2005), além de possuir recorte transversal por investigar a socialização em um determinado momento do tempo (HAIR JUNIOR et al., 2005), permitindo identificar a percepção dos participantes em um determinado momento do tempo.

Trata-se de um estudo de caso em uma única organização. Mediante autorização da Direção Geral, a pesquisa foi realizada em um campus do IFB, tendo, como população do estudo, o seu quadro funcional de 89 servidores públicos (43 técnicos e 46 docentes).

Foi utilizada abordagem mista (qualitativa e quantitativa), por meio da coleta de dados com questionário eletrônico estruturado em seis seções com 18 perguntas fechadas e duas perguntas abertas, para identificar a percepção dos servidores acerca da socialização na organização em que trabalham. A primeira e sexta seção contêm sete e oito itens de múltipla escolha, respectivamente. Ao final da primeira seção, havia pergunta-filtro quanto à participação em ação de socialização. A segunda seção possui oito itens para avaliação do grau de concordância em relação à socialização organizacional, em escala do tipo Likert de 5 pontos. Esses itens foram construídos a partir de Cunha (2016) e Dose, Ferreira e Reis (2008). Desses itens, seis referiam-se às ações de socialização enquanto dois, a seus resultados. A terceira seção havia pergunta filtro quanto à participação em treinamentos após o ingresso no IFB. Na quarta seção, alinhado à necessidade do estudo para saber percepção sobre participação em treinamentos, selecionaram-se sete itens da escala de instrumentos dos autores Borges et al. (2010), Azevedo (2013), Cunha (2016), Gonçalves (2016). Foi realizada validação semântica do questionário com quatro servidores do campus, o que permitiu obter contribuições no sentido de deixar as questões com fácil entendimento no momento de sua disponibilização. 
$\mathrm{O}$ instrumento foi enviado por e-mail aos servidores do campus, com convite para participação e link ao preenchimento (Google forms). Obteve-se retorno de 68 respondentes, aproximadamente em $76 \%$ do total, caracterizando-se como amostragem não probabilística por conveniência, devido a ter participação voluntária, mediante termo de consentimento livre e esclarecido. A amostra possui erro estatístico de $6 \%$, em um nível de confiança de $95 \%$, caracterizando em quantidade suficiente para boa representatividade da população.

Os dados quantitativos foram analisados com estatística descritiva (frequência, média e desvio-padrão). Calculou-se, também, a média dos seis itens das ações de socialização para mensurar o constructo da socialização no IFB.

Nos dados qualitativos das perguntas abertas, utilizou-se análise de conteúdo de Bardin (2011), com emprego de procedimentos sistemáticos e objetivos, e triangulação da análise por quatro pesquisadoras. Os relatos com temáticas similares foram agrupados para definição das categorias, sendo que cada uma delas tem as respectivas descrições e quantitativos de relatos.

\section{RESULTADOS E DISCUSSÕES}

Entre os servidores participantes desta pesquisa, $60,3 \%$ são do sexo masculino, com faixa etária de maior representatividade 30 a 35 anos de idade $(48,5 \%)$, seguida da faixa entre 24 e 29 anos $(20,6 \%) ; 54,4 \%$ são casados/união estável e $36,8 \%$ são solteiros; $36,8 \%$ possuem mestrado e $28 \%$ especialização, ou seja, $64,8 \%$ possuem algum tipo de pós-graduação; $50 \%$ são docentes e $50 \%$ técnicos. Quanto à lotação, $75 \%$ dos servidores estão na Diretoria de Ensino, Pesquisa e Extensão; 19,1\%, na Direção de Administração e Planejamento, e 5,9\%, na Direção Geral. O tempo de ingresso desses servidores consiste em $42,6 \%$ entre 1 e 2 anos no IFB, 25\% há mais de 4 anos, e $20,6 \%$ entre 3 e 4 anos.

Em relação ao recebimento de orientações e esclarecimentos quanto às atividades que os servidores iriam desenvolver, 39,7\% informaram que os obtiveram parcialmente, sendo que
$20,6 \%$ desse resultado foram de docentes e, ainda, $27,9 \%$ não tiveram esta prática. Com isso, $76,5 \%$ dos servidores indicaram que cometeram algum erro em decorrência do desconhecimento de suas atribuições ou rotinas de trabalho, sendo, na mesma proporção, com docentes e técnicos. A derrota ou o êxito dos profissionais dependem de como foi realizado o processo de socializá-los, uma vez que, durante esse período, ele vai adquirir conhecimentos e habilidades essenciais no desempenho de suas tarefas (VAN MAANEN; SCHEIN, 1979; AMARO, 2016).

Quanto ao processo de aprendizagem das atividades relativas ao cargo, $64,7 \%$ dos servidores receberam orientações dos colegas mais experientes. Ao comparar com Brum et al. (2014), que constataram esta ocorrência em 52\% da amostra, foi possível notar que a iniciativa do IFB ocorreu em mais casos. Ainda sobre esse processo, $58,8 \%$ foram assessorados pela chefia imediata, 55,9\% disseram que as experiências profissionais anteriores ajudaram nesse processo, $52,9 \%$ afirmaram que a aprendizagem aconteceu por conta própria, $36,8 \%$ utilizaram documentos internos (manuais) para exercerem suas atribuições, isto é, todas as formas de aprendizado são válidas e úteis para ajudar o novo servidor. Para as orientações que foram repassadas pela chefia imediata, podem-se utilizar as estratégias formais ou por investidura e, no caso das informações que foram transmitidas pelos colegas, as estratégias informais e as estratégicas em série (VAN MAANEN, 1996).

Com relação ao relacionamento interpessoal com a chefia imediata e com os colegas, os participantes classificaram como bom a excelente $89,7 \%$ e $83,8 \%$, respectivamente. Quando o servidor ingressou no órgão, 45,6\% opinaram que foram levados em consideração seus conhecimentos, suas habilidade e atitudes. Ratificando isso, Brum et al. (2014) afirmam que, quando o novato se sente parte do ambiente, ele realizará suas tarefas com dedicação, eficiência e eficácia, visando sempre ao sucesso profissional e ao organizacional.

No quesito de participação do servidor em programa de integração e treinamento após 
sua chegada, os índices foram 51,5\% e 55,9\%, respectivamente. Dos que não participaram em ambos os programas, o resultado que prevaleceu foi de técnicos com $29,4 \%$ sem integração e $23,5 \%$ sem treinamento. Nos estudos realizados por Cunha (2016) e Pacheco (2015), em instituições de ensino superior públicas, o nível de participação em ações de integração foi de $80,6 \%$, sendo maior ao do IFB, já a participação em treinamentos foi muito próxima do percentual encontrado (51\%). É possível inferir que o IFB está com nível mediano em promover a socialização organizacional. Assim, surge a necessidade de implementar esses programas com o intuito de profissionalizar os servidores para que eles entendam sua função e tornem-se eficientes e eficazes ao executarem as atividades pertinentes ao cargo (AIRES; FERREIRA, 2016; AMORIM; SILVA, 2012).

A partir das ações utilizadas pelo IFB, pode-se constatar que $88,6 \%$ concordaram conheceram todas as dependências do campus, $48,6 \%$ obtiveram conhecimento das normas e procedimentos do instituto, $54,3 \%$ indicaram que conheceram a história, a missão, a visão e os valores. $85,7 \%$ indicaram que foram apresentados aos outros colegas, $42,9 \%$ discordaram que foram socializados formalmente por seus colegas e 48,6\% afirmaram que houve, de maneira informal, essa socialização. Corroborando esses resultados, o estudo realizado em um determinado Instituto Federal demonstrou que $57 \%$ dos servidores desconhecem informações essenciais do próprio Instituto (GENARI, IBRAHIM, C.; HIBRAIM, G., 2017). Tendo em vista que a socialização cria um ambiente acolhedor, todas essas ações adotadas pelos órgãos são relevantes e, caso falte alguma, pode vir a ser uma barreira na assimilação do conteúdo das tarefas do recém-chegado, ocasionando, assim, baixo desempenho (SILVA; FOSSÁ, 2013; TEODORO, 2015).

A Tabela 1 apresenta as médias e os desvios-padrões da percepção dos servidores quanto à consolidação da socialização organizacional e de sua contribuição e resultados.
Tabela 1 - Consolidação da percepção da socialização organizacional

\begin{tabular}{c|c|c|c|c|c|c}
\hline \multirow{2}{*}{ Itens } & \multicolumn{2}{|c|}{ Docentes } & \multicolumn{2}{c|}{ Técnicos } & \multicolumn{2}{c}{ Geral } \\
\cline { 2 - 7 } & Média & DP & Média & DP & Média & DP \\
\hline $\begin{array}{c}\text { Socialização } \\
\text { Organizacional }\end{array}$ & 3,5 & 0,8 & 3,4 & 0,9 & 3,5 & 0,8 \\
\hline $\begin{array}{c}\text { Contribuição } \\
\text { da integração } \\
\text { à adaptação ao } \\
\text { campus }\end{array}$ & 3,7 & 1,3 & 4,1 & 1,1 & 3,9 & 1,2 \\
\hline $\begin{array}{c}\text { Resultados } \\
\text { satisfatórios da } \\
\text { integração }\end{array}$ & 3,5 & 1,2 & 3,7 & 1,3 & 3,6 & 1,2 \\
\hline $\begin{array}{c}\text { Resultados } \\
\text { satisfatórios do } \\
\text { treinamento }\end{array}$ & 3,7 & 0,9 & 3,9 & 0,8 & 3,8 & 0,8 \\
\hline
\end{tabular}

Fonte: dados da pesquisa.

De acordo com os resultados obtidos, o nível de percepção dos técnicos e dos docentes está muito próximo quando se trata da socialização organizacional em geral, o que, de certo modo, representa homogeneidade na visão que ambos têm do processo de socializar os novos servidores, e, ainda, enfatiza a primeira parte do objetivo deste estudo de demonstrar a percepção dos participantes em relação ao processo de socialização no contexto do órgão. Fazendo uma comparação com o estudo de Carvalho, Borges e Vikan (2012), a média encontrada foi de 4,4 (DP=0,6), o que demonstra um nível de concordância acima do encontrado na amostra do IFB. Com isso, o instituto precisa adotar o processo de integração como uma ferramenta estratégica viável na melhoria das ações realizadas, conforme indicado por Cunha (2016).

Quanto à contribuição da integração para a adaptação do novo servidor e a satisfação dos resultados com ela, verificou-se que os técnicos possuem percepção de terem maiores ganhos em relação aos docentes. Vale ressaltar que ambos os grupos de servidores, ou seja, 74,3\% concordaram que a contribuição existe, e $62,9 \%$ afirmaram que os resultados desse programa são satisfatórios, o que converge com a pesquisa de Cunha (2016), que obteve $59 \%$ de satisfação desse processo, confirmando que $60 \%$ dos servidores das duas instituições estudadas estão satisfeitos com a socialização realizada no ambiente de trabalho. Porém, 
se comparado ao estudo realizado por Brum et al. (2014), há divergência, pois mais da metade (52\%) responderam que estão pouco satisfeitos com a socialização.

Dos respondentes que confirmaram a participação no programa de treinamento, 78,9\% concordaram que suas atividades ganharam qualidade; $63,2 \%$ asseguraram que as tarefas foram executadas com mais rapidez; $50 \%$ admitiram que o tempo de treinamento foi suficiente para a obtenção de conhecimentos; $84,2 \%$ ratificaram que dominam as suas atribuições, e $86,8 \%$ alegaram que conhecem os procedimentos para executar suas atividades. Pelo fato de quase todos os percentuais estarem com bom nível de concordância, infere-se que, quando o servidor recebe treinamento adequado, consegue percebê-lo como uma prática útil e eficiente no desempenho da função (DELOBBE; COOPER-THOMAS; HOE, 2016).

O compartilhamento do conhecimento adquirido no treinamento foi realizado por $86,8 \%$ dos servidores, e $71,1 \%$ indicaram que o progra- ma foi satisfatório, sendo que os técnicos possuem maior satisfação que os docentes (Tabela 1). Esses resultados aproximaram-se do que foi verificado por Gonçalves (2016) que, em 91,5\% dos casos, o conhecimento foi compartilhado, e 77\%, asseguraram satisfação em participar do programa. Devido à percepção positiva quanto ao efeito desse programa, denota-se que sua necessidade contribui com o desenvolvimento de competências profissionais, para que o ingressante possa realizar suas tarefas com adequado desempenho, agilidade e rapidez (MARRAS, 2009; MAGALHÃES et al., 2010; TEÓFILO et al., 2013).

Com o intuito de aprofundar a percepção dos servidores acerca da socialização organizacional, foram levantadas as dificuldades no processo de adaptação e integração, alinhado ao objetivo desta pesquisa, obtendo respostas de $88 \%$ da amostra, os quais apresentaram 70 relatos. Ao analisá-los, foi possível estabelecer oito categorias distintas, as quais são apresentadas no Quadro 2, com suas respectivas descrições, exemplos e quantitativos dos relatos.

Quadro 2 - Dificuldades no processo de socialização organizacional

\begin{tabular}{|c|c|c|c|}
\hline Categoria & Descrição & Exemplos de Relatos & $\begin{array}{l}\text { Quant. de } \\
\text { Relatos } \\
\text { (\% do total) }\end{array}$ \\
\hline $\begin{array}{l}\text { 1. Ausência de } \\
\text { treinamento }\end{array}$ & $\begin{array}{l}\text { Refere-se à falta de conhecimento } \\
\text { específico da área de atuação. }\end{array}$ & $\begin{array}{l}\text { "Não houve treinamento } \\
\text { específico e aplicado ao trabalho } \\
\text { realizado no setor" }\end{array}$ & $10(14,3 \%)$ \\
\hline $\begin{array}{l}\text { 2. Inexperiência } \\
\text { profissional } \\
\text { específica para } \\
\text { exercer o cargo }\end{array}$ & $\begin{array}{c}\text { Refere-se à falta de experiência na } \\
\text { execução das atribuições específicas } \\
\text { do cargo no contexto da vaga } \\
\text { ocupada. }\end{array}$ & $\begin{array}{l}\text { "Como era meu primeiro } \\
\text { emprego público, não tinha } \\
\text { experiência na área" }\end{array}$ & $4(5,7 \%)$ \\
\hline $\begin{array}{l}\text { 3. Falta de apoio } \\
\text { de colegas/chefia }\end{array}$ & $\begin{array}{c}\text { Refere-se em não receber } \\
\text { orientações e apoio da chefia } \\
\text { imediata e/ou dos colegas durante a } \\
\text { realização das tarefas. }\end{array}$ & $\begin{array}{c}\text { "Os servidores mais antigos } \\
\text { não se preocupam em repassar } \\
\text { o aprendizado aos novos } \\
\text { servidores" }\end{array}$ & $10(14,3 \%)$ \\
\hline $\begin{array}{l}\text { 4. Limitações } \\
\text { dos Normativos } \\
\text { Institucionais }\end{array}$ & $\begin{array}{l}\text { Refere-se à insuficiência e à } \\
\text { inadequação de manuais, fluxos } \\
\text { e regulamentos institucionais nas } \\
\text { rotinas de trabalho. }\end{array}$ & $\begin{array}{l}\text { "Falta de manuais de } \\
\text { procedimentos" }\end{array}$ & $16(22,9 \%)$ \\
\hline $\begin{array}{l}\text { 5. Falta de } \\
\text { Esclarecimento e } \\
\text { Direcionamento } \\
\text { das Atribuições }\end{array}$ & $\begin{array}{l}\text { Refere-se ao desconhecimento das } \\
\text { atribuições a serem desempenhadas } \\
\text { no setor. }\end{array}$ & $\begin{array}{l}\text { "Desconhecimento das funções } \\
\text { de cada servidor/setor" }\end{array}$ & $9(12,9 \%)$ \\
\hline
\end{tabular}




\begin{tabular}{|c|c|c|c|}
\hline Categoria & Descrição & Exemplos de Relatos & $\begin{array}{c}\text { Quant. de } \\
\text { Relatos } \\
\text { (\% do total) }\end{array}$ \\
\hline $\begin{array}{c}\text { 6. Desconheci- } \\
\text { mento de informa- } \\
\text { ções institucionais }\end{array}$ & $\begin{array}{c}\text { Refere-se à ausência de } \\
\text { conhecimento de informações da } \\
\text { execução das atividades do setor } \\
\text { e a estruturação das áreas e do seu } \\
\text { planejamento. }\end{array}$ & $\begin{array}{c}\text { "Falta de conhecimento da } \\
\text { documentação pertinente ao } \\
\text { setor" }\end{array}$ & $13(18,6 \%)$ \\
\hline $\begin{array}{c}\text { 7. Entraves na } \\
\text { comunicação }\end{array}$ & $\begin{array}{c}\text { Referem-se às intercorrências } \\
\text { nos debates para discussão de } \\
\text { assuntos pertinentes aos objetivos } \\
\text { institucionais. }\end{array}$ & "Falta de comunicação" & $3(4,3 \%)$ \\
\hline $\begin{array}{c}\text { 8. Inconsistências } \\
\text { na gestão } \\
\text { (organizacional) }\end{array}$ & $\begin{array}{c}\text { Referem-se às dificuldades de } \\
\text { deliberar de forma democrática nas } \\
\text { tomadas de decisões da Instituição. }\end{array}$ & $\begin{array}{c}\text { "Pouca participação democrática } \\
\text { e influência política (negativa) } \\
\text { sobre as decisões da gestão" }\end{array}$ & $5(7,1 \%)$ \\
\hline
\end{tabular}

Fonte: dados da pesquisa.

Com base nos relatos dos servidores, a principal dificuldade que o novo servidor enfrenta inicialmente consiste na limitação dos normativos institucionais. Devido à questão apresentada, as atividades internas ficam sem direcionamento, compromete o alcance dos objetivos organizacionais e, por conseguinte, os indivíduos ficam sem entender seu papel na instituição. Percebe-se a preocupação das entidades públicas em padronizar seus processos com a elaboração de documentos normativos, visando à melhoria contínua de seus serviços e o suporte necessário ao servidor no exercício de sua função (AIRES; FERREIRA, 2016; AMORIM; SILVA, 2012).

O segundo obstáculo enfrentado pelos servidores é o desconhecimento de informações institucionais pela falta do conhecimento referentes aos procedimentos de suas atribuições, o que pode ser decorrente do problema anterior. Silva e Fossá (2013) enfatizam o quanto isso dificulta a compreensão do conteúdo das tarefas por parte do novato e a continuidade dos processos; logo, o servidor não consegue desenvolver suas atividades, e estas ficam mais lentas, burocráticas e ineficientes.

Entre as categorias descritas acima, duas apresentaram percentuais semelhantes. A primeira é a ausência de treinamento que, geralmente, ocasiona retrabalhos, demora e falhas na execução das tarefas. Nos estudos de Freitas (2012), as organizações públicas têm-se preocupado em reverter essa questão ao capacitar seus servidores por intermé- dio do treinamento para a melhoria da prestação dos serviços à sociedade.

Na sequência, tem-se a falta de apoio e orientações por parte dos colegas e da chefia. Atrelados a essa dificuldade, estão os problemas de relacionamento. Além deles, outros fatores foram igualmente identificados por Brum et al. (2014), em estudo realizado em uma instituição pública, exercício das atividades com excesso de burocracia e entraves para aceitar novas ideias. Entretanto, destaca-se que a adversidade citada diverge do resultado encontrado nas respostas quanto às orientações pelos colegas $(64,7 \%)$ e por parte da chefia $(58,8 \%)$. Mesmo com uma frequência de $61,8 \%$ de concordância nesse aspecto, é possível depreender que, na percepção dos servidores, esse direcionamento para a execução das tarefas do cargo necessita de melhorias.

A inexperiência profissional $(5,7 \%)$ e a falta de orientação e esclarecimento das atribuições $(12,9 \%)$ são entraves que podem ser solucionados com uma cultura organizacional voltada ao compartilhamento de informações em todos os níveis, às interações com os colegas de trabalho e à prática do aprendizado social coletivo, visto que é por intermédio dos indivíduos que ocorrem as mudanças mais relevantes na instituição (ROBBINS, 2005; BEM; PRADO; DELFINO, 2013; MARTINELLI ; BRUM; WAECHTER, 2013; LIMA, 2016.). Há, também, os problemas de comunicação $(4,3 \%)$ e inconsistência na gestão $(7,1 \%)$, os quais preci- 
sam ser direcionados, dentro do contexto da socialização organizacional, pelos gestores a fim de ajudar o servidor a desenvolver, de forma eficiente e eficaz, suas atribuições por intermédio de uma comunicação que consiga alinhar os objetivos individuais aos da organização, anteveja possíveis riscos, estreite vínculos e impulsione um ambiente favorável, e, ainda, ponha um planejamento e consolidação no processo de aprendizagem (SILVA et al., 2014; RIBEIRO et al., 2017; TIBURCIO; SANTANA, 2014).

Ainda sobre o processo de socialização organizacional, foram elencados 69 relatos de sugestões de melhorias para a Instituição, por $88 \%$ da amostra. A análise gerou quatro categorias distintas apresentadas no Quadro 3, com suas respectivas descrições, exemplos e percentuais. de ações de melhorias no assunto em questão. A maioria concordou que deve haver práticas de ambientação assim que o servidor entrar em exercício. O intuito é promover um ambiente receptivo e acolhedor ao recém-chegado, familiarizá-lo com a cultura organizacional e orientá-lo quanto às suas atribuições (TEODORO, 2015). Conforme a descrição dos relatos sobre a ambientação, é possível utilizar algumas estratégias propostas por Van Maanen (1996), como as formais e as informais, as coletivas, que tendem a ser exitosas nesse contexto, e por investidura.

A segunda categoria de sugestão mais recorrente é a realização de programas de treinamentos específicos para promover conhecimentos de acordo com as atribuições que o servidor vai desempenhar no setor, tanto para o que está chegando,

Quadro 3 - Sugestões no processo de socialização organizacional

\begin{tabular}{|c|c|c|c|}
\hline Categoria & Descrição & Exemplos de Relatos & $\begin{array}{l}\text { Quant. de } \\
\text { Relatos } \\
\text { (\% do total) }\end{array}$ \\
\hline $\begin{array}{l}\text { 1. Práticas de } \\
\text { Ambientação }\end{array}$ & $\begin{array}{c}\text { Refere-se em fazer da socialização o } \\
\text { elemento primordial de acolhimento } \\
\text { e interação entre o servidor recém- } \\
\text { chegado e seus colegas, para melhor } \\
\text { adaptação ao novo ambiente de trabalho. }\end{array}$ & $\begin{array}{l}\text { “Oficinas de apresentação } \\
\text { das instâncias/servidores } \\
\text { responsáveis e dos fluxos } \\
\text { necessários para execução das } \\
\text { tarefas" }\end{array}$ & $36(52,2 \%)$ \\
\hline $\begin{array}{l}\text { 2. Programas de } \\
\text { Treinamento }\end{array}$ & $\begin{array}{l}\text { Refere-se a promover e disponibilizar } \\
\text { treinamentos específicos e periódicos } \\
\text { da área de atuação tanto aos novos } \\
\text { ingressantes quantos aos veteranos. }\end{array}$ & $\begin{array}{l}\text { "Treinamento de gestores, } \\
\text { curso de formação para novos } \\
\text { servidores, curso de reciclagem } \\
\text { para os antigos servidores" }\end{array}$ & $15(21,7 \%)$ \\
\hline $\begin{array}{l}\text { 3. Elaboração } \\
\text { e Padronização } \\
\text { de Fluxos e } \\
\text { Normativos }\end{array}$ & $\begin{array}{l}\text { Refere-se à produção das normas } \\
\text { institucionais e rotinas de trabalho de } \\
\text { forma planejada e padronizada. }\end{array}$ & $\begin{array}{l}\text { "Implementação de manuais e } \\
\text { formulários padronizados" }\end{array}$ & $8(11,6 \%)$ \\
\hline $\begin{array}{l}\text { 4. Orientações } \\
\text { sobre Processos } \\
\text { Institucionais }\end{array}$ & $\begin{array}{l}\text { Refere-se a instruir o servidor acerca } \\
\text { das normas e dos procedimentos da } \\
\text { instituição, avaliar suas aptidões e } \\
\text { alocá-lo no setor que seja de acordo } \\
\text { com suas experiências profissionais. }\end{array}$ & $\begin{array}{l}\text { "Informar missão, valores do } \\
\text { IFB, o eixo/área de atuação do } \\
\text { Campus, reforçar as atribuições } \\
\text { do cargo, os possíveis níveis } \\
\text { de atuação, o fluxo de trabalho, } \\
\text { orientar sobre documentos/ } \\
\text { formulários importantes" }\end{array}$ & $10(14,5 \%)$ \\
\hline
\end{tabular}

Fonte: dados da pesquisa.

A partir das informações apresentadas, os servidores contribuiriam com sugestões para o aperfeiçoamento da socialização organizacional no órgão em estudo, cumprindo com a última parte do objetivo deste trabalho quanto à identificação quanto para aquele que está há mais tempo no órgão. O resultado da pesquisa de Gonçalves (2016) corrobora esse anseio, haja vista que a maioria dos participantes ficou satisfeita em participar do treinamento, em aplicá-lo às tarefas cotidianas e com- 
partilhar o que aprenderam com os outros servidores. Ademais, outros efeitos podem ser percebidos - compromisso com a organização, desempenho eficaz e satisfação nas atividades desenvolvidas (BAUER et al., 2007).

Os dois últimos quesitos foram considerados sensivelmente pelos respondentes. Disponibilizar aos servidores manuais, formulários padronizados e rotinas institucionais $(11,6 \%)$ se faz necessário para maximizar a socialização, e, assim, contribuir com a melhoria da compreensão das atividades e da própria instituição e a simplificação dos procesSOS (COOPER-THOMAS; ANDERSON; CASH 2012; PACHECO, 2015). Entretanto, é válido atrelar esse aspecto à instrução das normas e dos processos do órgão $(14,5 \%)$ para que se tenham indivíduos preparados e confiantes no desempenho de suas atribuições, considerem a hierarquia e acatem as regras. Caso isso não aconteça, pode comprometer a rotina de trabalho no setor em que está alocado (CARVALHO; BORGES; VIKAN, 2012; PACHECO, 2015).

\section{CONSIDERAÇÕES FINAIS}

Partindo da finalidade deste estudo, que é a percepção dos servidores do órgão em estudo em relação ao processo de socialização e a identificação das dificuldades de adaptação e o que pode ser aperfeiçoado nesse processo, pode-se dizer que esses objetivos foram alcançados. No que tange à primeira parte do objetivo, todos os servidores participantes relataram suas percepções relacionadas ao processo de socialização organizacional (integração e treinamento) nos primeiros meses, após a entrada em exercício, sendo possível demonstrar que a maioria percebe a relevância da socialização organizacional em relação ao desempenho das atividades. Conforme as respostas dos participantes, a integração contribuiu na adaptação deles $(74,3 \%)$; admitiram que, ao serem orientados por seus colegas e pela chefia, tiveram mais facilidade no processo de aprendizagem $(61,8 \%)$; concordaram que, após o treinamento, as atividades adquiriram qualidade $(78,9 \%)$; passaram a ter domínio de suas atribuições $(84,2 \%)$ e conheceram os procedimentos necessários à execução das tarefas
(86,8\%). Além disso, mais de $88 \%$ descreveram as dificuldades enfrentadas e as possíveis ações de aperfeiçoamento do assunto em questão.

Logo após, foram mencionados os principais obstáculos que se referiram à falta de conhecimento de informações do órgão, seguido da inexistência de treinamento para atividades específicas do setor, ausência de apoio e orientações dos colegas e da chefia para a realização das tarefas e esclarecimento das atribuições, falta de documentos normativos e procedimentos para direcionar os processos de trabalho, pouca ou nenhuma experiência profissional do recém-chegado, entraves nos diálogos e falhas na gestão organizacional. Esses fatores, segundo eles, causam impactos negativos, resultando na descontinuidade dos processos, nos fluxos lentos e ineficientes e nas falhas de execução.

E, por fim, os participantes da pesquisa sugeriram ações que consideram relevantes à socialização. As práticas de ambientação, como encontros informais, dinâmicas em grupo, eventos comemorativos, podem fazer diferença na vida pessoal e profissional dos servidores em geral, uma vez que buscam ofertar um ambiente acolhedor e receptivo. A segunda opção foi a realização periódica de programas de treinamentos para o aperfeiçoamento contínuo do servidor, tanto novos quanto veteranos, de modo a contribuir com a melhoria dos seus desempenhos. Outra sugestão consistiu em instruir o servidor acerca dos manuais de procedimentos e das normas institucionais, para que ele conheça a instituição em todos os seus aspectos.

Apesar da disponibilização do formulário eletrônico durante tempo suficiente, do uso de diferentes estratégias para coleta dos dados, inclusive a solicitação para participar pelo Diretor Geral do Campus, houve limitação no estudo para a obtenção de maior amostra, devido à não participação de servidores por motivo de férias, licenças, afastamentos e os demais, por motivos não identificados. Isso levou a uma amostra de aproximadamente $76 \%$ do total de respondentes, o que não comprometeu o nível de confiança da pesquisa, conforme descrito no método.

As contribuições e justificativas propostas inicialmente pela pesquisa demonstraram que a socialização organizacional, com o apoio de com- 
provados estudos similares em órgãos públicos, é uma ferramenta estratégica que pode influenciar, positivamente, no desempenho das atividades e, consequentemente, na qualidade da prestação de serviços à sociedade. Contribuiu, também, com relato da percepção dos servidores no tocante às dificuldades e às sugestões nos processos de socialização do órgão, tanto para ciência ao órgão, como para outras organizações públicas, para analisarem e aperfeiçoarem o processo de socialização a seus respectivos contextos organizacionais, além de incluírem as propostas em seus planejamentos, de modo a evitarem os problemas apresentados e, assim, estabelecerem ações que promovam o desenvolvimento individual e institucional.

Sugerem-se novos estudos sobre socialização organizacional, podendo ser: (1) em organizações públicas, para identificar as práticas utilizadas e os efeitos nos resultados do desempenho dos servidores e na prestação do serviço à sociedade; (2) em organizações privadas, para identificar práticas que possam servir de exemplo para outras organizações; (3) estudos comparados em organizações públicas e privadas do mesmo contexto, por exemplo, de ensino superior, para identificar os efeitos das práticas em diferentes contextos. Quanto ao método, recomenda-se (1) o uso de estudos longitudinais para acompanhar os efeitos das diferentes ações no desempenho individual e organizacional ao longo do tempo; (2) o uso de múltiplas fontes de coleta de dados; (3) o uso das categorias identificadas neste estudo quanto às dificuldades e às sugestões para complemento dos itens do questionário a ser aplicado; (4) o uso de estatística inferencial e multivariada, para buscar evidências de validade no instrumento, identificar possíveis correlações e diferenças significativas na percepção de diferentes grupos, ou, até mesmo, variáveis preditivas da socialização com uso de regressões.

\section{REFERÊNCIAS}

AIRES, V. F. G.; FERREIRA, V. P. Motivação: importante ferramenta para gestão de pessoas no setor público. Humanidades \& Inovação, Tocantins, v. 3, n. 1, p. 66-77, 2016.
AMARO, J. P. S. O acolhimento e integração como preditores da identificação organizacional. 2016. 87 f. Tese (Mestrado em Psicologia) Instituto Universitário de Ciências Psicológicas, Sociais e da Vida - ISPA, Lisboa, 2016.

AMORIM, T. N. G. F.; SILVA, L. B. Treinamento no serviço público: uma abordagem com servidores técnico-administrativos de universidade. Teoria e Prática em Administração, Tocantins, v. 2, n. 1, p. 1-28, 2012.

ANDRADE, G. A. Comprometimento organizacional: um estudo com os servidores técnico-administrativos de uma instituição de ensino superior. 2015. 123 f. Tese (Mestrado em Gestão Pública) - Universidade Federal de Pernambuco UFP, Recife, 2015.

AZEVEDO, M. P. Modelo para avaliar o impacto dos treinamentos do Instituto Federal do Amazonas. 2013. 120 f. Tese (Mestrado em Engenharia de Produção) - Universidade Federal do Amazonas - UFAM, Manaus, 2013.

BARDIN, L. Análise de conteúdo. São Paulo: Edição 70, 2011.

BAUER, T. N. et al. Newcomer adjustment during organizational socialization: a metaanalytic review of antecedents, outcomes, and methods. Journal of Applied Psychology by the American Psychological Association, Washington, v. 92, n. 3, p. 707-721, 2007.

BEM, R. M.; PRADO, M. L.; DELFINO, N. Desafios à implantação da gestão do conhecimento: a questão cultural nas organizações públicas federais brasileiras. Revista Digital de Biblioteconomia e Ciência da Informação, Campinas, v. 11, n. 2, p. 123-135, 2013.

BORGES, L. O. et al. Re-construção e validação de um inventário de socialização organizacional. Revista de Administração Mackenzie, São Paulo, v. 11, n. 4, p. 4-37, 2010. 
BRUM, T. M. M. et al. A influência da socialização e integração na satisfação dos servidores públicos: um estudo de caso em uma organização pública. Desafio Online, Campo Grande, v. 2, n. 1, p. 465-486, 2014.

CARVALHO, V. D.; BORGES, L. O.; VIKAN, A. Socialização organizacional: estudo comparativo entre servidores públicos brasileiros e noruegueses. Revista Eletrônica de Administração REAd, Porto Alegre, v. 72, n. 2, p. 339-371, 2012.

CHAO, G. T. Organizational socialization: background, basics, and a blueprint for adjustment at work. In: KOZLOWSKI, W. J. (ed.). The Oxford Handbook of Organizational. Michigan: [s.n.], 2012. v. 1.

COOPER-THOMAS, H.; ANDERSON, N.; $\mathrm{CASH}, \mathrm{M}$. Investigating organizational socialization: a fresh look at newcomer adjustment strategies. Personnel Review, Bingley, v. 41, n. 1, p .41-55, 2012.

CUNHA, J. P. Análise do processo de socialização de novos servidores técnicos-administrativos em educação da UFSC. 2016. 247 f. Tese (Mestrado em Administração Universitária) - Universidade Federal de Santa Catarina - UFSC, Florianópolis, 2016.

DELOBBE, N.; COOPER-THOMAS, H.; HOE, H. de. A new look at the psychological contract during organizational socialization: the role of newcomers' obligations at entry. Journal of Organizational Behavior, Hoboken, v. 37, p. 845-867, 2016.

DOSE, C. A.; FERREIRA, C. D.; REIS, D. C. J. Integração do servidor público ao ambiente de trabalho: o caso de Barra Mansa. 2008. $62 \mathrm{f}$. TCC (Pós-Graduação em Administração Pública) - Fundação Getúlio Vargas, Rio de Janeiro, 2008.

FREITAS, M. A. P. G. Treinamento e desenvolvimento em Instituições Federais de Ensino. 2012. 83 f. Tese (Mestre em Administração) - Faculdade de Ciências Empresariais da Universidade - FUMEC, Minas Gerais, 2012.
GENARI, D.; IBRAHIM, C. V. D.; IBRAHIM, G. F. A Percepção dos Servidores Públicos Sobre a Socialização Organizacional: um estudo no Instituto Federal de Educação, Ciência e Tecnologia do Rio Grande do Sul. Revista Holos, Rio Grande do Norte, v. 5, p. 313-328, 2017.

GONÇALVES, P. R. Avaliação de impacto de ações de capacitação na área administrativa em uma instituição federal de ensino superior. 2016. 87 f. Tese (Mestrado em Gestão de Processos Institucionais) - Universidade Federal do Rio Grande do Norte, Natal, 2016.

GONDIM, S. M. G.; SOUZA, J. J.; PEIXOTO, A. L. A. Gestão de pessoas. In: BORGES, L. O.; MOURÃO, L. (org.). O trabalho e as organizações a partir da psicologia. Porto Alegre: Artmed, 2013.

HAIR JUNIOR, J. F. et al. Fundamentos de Métodos de Pesquisa em Administração. Porto Alegre: Bookman, 2005.

IMAI, C. A. P.; BOTOLOTO, D. C.; BAPTISTA, N. L. O Programa de Acompanhamento de Novos Servidores do Inmetro. In: VI CONGRESSO CONSAD DE GESTÃO PÚBLICA, 6., 2013, Brasília. Anais [...]. Brasília: Consad, 2013.

LIMA, K. A. O plano de desenvolvimento institucional como facilitador para a gestão do conhecimento no setor público: o caso do IF Goiano. 2016. 76 f. Tese (Mestrado em Desenvolvimento Regional) - Faculdade Alves Farias, Goiânia, 2016.

MAGALHÃES, E. M. et al. A política de treinamento dos servidores técnico-administrativos da Universidade Federal de Viçosa na percepção dos treinados e dos dirigentes da instituição. Revista de Administração Pública, Rio de Janeiro, v. 1, p. 55-86, 2010.

MARRAS, J. P. Administração de Recursos Humanos. 13. ed. São Paulo: Saraiva, 2009. 
MARTINELLI, S. G.; BRUM, T. M. M.; WAECHTER, L. Detalhes decisivos no ingresso e dia-a-dia do servidor público que podem melhorar o desempenho das organizações públicas. In: SEGET - SIMPÓSIO DE EXCELÊNCIA EM GESTÃO E TECNOLOGIA, 10., 2013, Resende, RJ. Anais [...]. Resende, RJ: Seget, 2013.

MOYSON, S. et al. Organizational socialization in public administration research: a systematic review and directions for future research. The American Review of Public Administration, Califórnia, v. 48, n. 6, p. 610-627, 2017.

PACHECO, T. T. O. A socialização organizacional no contexto da UFRN: proposta de curso de iniciação ao serviço público. 2015. 104 f. Tese (Mestrado em Gestão de Processos Institucionais) - Universidade Federal do Rio Grande do Norte, 2015.

PINTO, M. C. F.; SILVA, F. M. Gestão de pessoas na administração pública brasileira: uma análise sobre sua evolução histórica e o atual contexto em transformação. Revista Eletrônica do Tribunal de Contas do Estado do Rio Grande do Sul, Porto Alegre, v. 1, n. 2, p. 1-16, 2015.

RIBEIRO, C. V. S.; MANCEBO, D. O servidor público no mundo do trabalho do século XXI. Psicologia: Ciência e Profissão, Brasília, v. 33, n. 1, p. 192-207, 2013.

RIBEIRO, R. S. et al. Análise do perfil dos servidores técnico-administrativos de uma Ife após a promulgação da Lei Federal 11.091/2005. Revista Gestão em Análise, Fortaleza, v. 6, n. 1/2, p. 88101, 2017.

ROBBINS, S. P. Comportamento Organizacional. 11. ed. São Paulo: Pearson Prentice Hall, 2005.

SILVA, A. H.; FOSSÁ, M. I. T. O processo de socialização organizacional como estratégia de integração indivíduo e organização. REUNA, Belo Horizonte, v. 18, n. 4, p. 5-20, 2013.
SILVA, A. O. et al. Estratégias de socialização: a forma mais eficaz para a integração entre indivíduo e organização. In: SEGET - SIMPÓSIO DE EXCELÊNCIA EM GESTÃO E TECNOLOGIA, 10., 2014, Rio de Janeiro. Anais [...]. Rio de Janeiro: Seget, 2014.

TEODORO, A. N. G. Linguagem não verbal na integração de novos funcionários. 2015. 29 f. Artigo Científico (Bacharel em Administração) Faculdade de Pindamonhangaba -FAPI, Pindamonhangaba, 2015.

TEÓFILO, A. T. et al. Treinamento como ferramenta estratégica para o desenvolvimento corporativo. In: SEGET - SIMPÓSIO DE EXCELÊNCIA EM GESTÃO E TECNOLOGIA, 10., 2013, Resende, RJ. Anais [...]. Resende, RJ: Seget, 2013.

TIBURCIO, J. S.; SANTANA, L. C. A comunicação interna como estratégia organizacional. Revista de Iniciação Científica Cairu, v. 1, p. 13-26, jun. 2014.

VAN MAANEN, J.; SCHEIN, E. H. Toward a Theory of Organizational Socialization. Research in organizational behavior, Massachusetts, v. 1, p. 209-264, 1979.

VAN MAANEN, John. Processando as pessoas: estratégias de socialização organizacional. In: FLEURY, Maria Tereza Leme; FISCHER, Rosa Maria (coord.). Cultura e poder nas organizações. São Paulo: Atlas, 1996. 